University of Nebraska - Lincoln

DigitalCommons@University of Nebraska - Lincoln

Craig J. Eckhardt Publications

Published Research - Department of Chemistry

October 1977

\title{
Thermochromism in a polydiacetylene crystal
}

\author{
R.R. Chance \\ Allied Chemical Corporation, Morristown, New Jersey \\ R.H. Baughman \\ Allied Chemical Corporation, Morristown, New Jersey \\ H. Muller \\ University of Nebraska - Lincoln \\ Craig J. Eckhardt \\ University of Nebraska - Lincoln, ceckhardt1@unl.edu
}

Follow this and additional works at: https://digitalcommons.unl.edu/chemistryeckhardt

Part of the Chemistry Commons

Chance, R.R.; Baughman, R.H.; Muller, H.; and Eckhardt, Craig J., "Thermochromism in a polydiacetylene crystal" (1977). Craig J. Eckhardt Publications. 38.

https://digitalcommons.unl.edu/chemistryeckhardt/38

This Article is brought to you for free and open access by the Published Research - Department of Chemistry at DigitalCommons@University of Nebraska - Lincoln. It has been accepted for inclusion in Craig J. Eckhardt Publications by an authorized administrator of DigitalCommons@University of Nebraska - Lincoln. 


\title{
Thermochromism in a polydiacetylene crystal
}

\author{
R. R. Chance and R. H. Baughman \\ Materials Research Center, Allied Chemical Corporation, Morristown. New Jersey 07960
}

H. Müller and C. J. Eckhardt

Department of Chemistry, University of Nebraska, Lincoln, Nebraska 68588

(Received 9 May 1977)

\begin{abstract}
Specular reflection spectra are reported for a thermochromic polydiacetylene crystal, ETCD [substituent group - $\left(\mathrm{CH}_{2}\right)_{4} \mathrm{OCONHC}_{2} \mathrm{H}_{5}$ ] over the temperature range $23-130^{\circ} \mathrm{C}$. A reversible thermochromic phase change occurs at $\sim 120^{\circ} \mathrm{C}$ and is accompanied by a $2750 \mathrm{~cm}^{-1}$ blue shift in the reflection spectra. Evidence is presented which strongly suggests that the dramatic change in optical properties of ETCD at the phase transition is due to an acetylene to butatriene transformation in the bonding sequence of the polydiacetylene backbone
\end{abstract}

Polydiacetylenes are synthesized via a solid-state 1,4addition reaction of diacetylene crystals of the form $\mathrm{R}-\mathrm{C} \equiv \mathrm{C}-\mathrm{C} \equiv \mathrm{C}-\mathrm{R} .{ }^{1,2}$ There are two extreme representations for the bonding sequence in the polymer backbone: (1) an acetylene structure $\neq \mathrm{RC}-\mathrm{C} \equiv \mathrm{C}-\mathrm{CR} \neq$, and (2) a butatriene structure $(\mathrm{RC}=\mathrm{C}=\mathrm{C}=\mathrm{CR}+$. Electron delocalization will tend to decrease the degree of bond alternation in these two structures so that observed structures can be viewed-at least qualitatively-as resonance admixtures of the two extremes. Polydiacetylene crystals which are very close to the two extremes have now been observed: PTS ( $\mathrm{R}$ is $-\mathrm{CH}_{2} \mathrm{SO}_{3} \mathrm{C}_{6} \mathrm{H}_{4} \mathrm{CH}_{3}$ ) is best represented with the acetylene backbone, ${ }^{3}$ and TCDU [R is$\left.\left(\mathrm{CH}_{2}\right)_{4} \mathrm{OCONHC}_{6} \mathrm{H}_{5}\right]$ is best represented by the butatriene sequence. ${ }^{4}$ The observed bond lengths are tabulated in Table I along with those expected for "ideal" acetylene ${ }^{5}$ and butatriene backbones. ${ }^{6}$

TCDU has recently been shown to undergo a first-order phase transition at high pressures ( $\gtrsim 5 \mathrm{kbar}$ ) or at low temperatures $\left(\lesssim 100^{\circ} \mathrm{K}\right) .^{7}$ This reversible phase change is accompanied by changes in electronic structure, as determined by resonance Raman spectroscopy. ${ }^{7}$ The electronic structure change has been attributed to a change in backbone bonding sequence: butatriene at high temperature (low pressure) to acetylene at low temperature (high pressure). In this paper, we discuss another polydiacetylene, ETCD [R is $\left.-\left(\mathrm{CH}_{2}\right)_{4} \mathrm{OCONHC}_{2} \mathrm{H}_{5}\right]$. This compound is chemically very similar to TCDU and also undergoes a phase transition with Raman spectral changes $^{8,9}$ which are quite similar to those in TCDU. ${ }^{7}$ Here we present normal incidence reflectivity measurements for ETCD as a function of temperature and show that the electronic structure changes at the phase transition in ETCD are also consistent with an acetylene to butatriene transformation in the polydiacetylene backbone.

The normal incidence reflectivity of ETCD as a function of temperature is shown in Fig. 1. (Experimental apparatus ${ }^{10,11}$ and crystal preparation ${ }^{8,12}$ have been decribed elsewhere.) At $115^{\circ} \mathrm{C}$ the reflection spectrum changes abruptly, indicating the onset of the thermochromic phase change. At $130^{\circ} \mathrm{C}$ the phase change is complete and there are no further qualitative changes in the spectra up to at least $180^{\circ} \mathrm{C}$. As long as the crystal is not severely overheated, the process is re- versible, with the reverse transition occurring at $\sim 70$ ${ }^{\circ} \mathrm{C}$. The large hysteresis would indicate a first order phase change.

The hysteresis loops for the absorption edge and for the reflectivity at $15750 \mathrm{~cm}^{-1}$ (reflection peak at room temperature) are shown in Fig. 2. The absorption edge is arbitrarily defined in a transmission mode. The data shown in Figs. 1, 2(a), and 2(b) are for three separate crystals and are in good agreement with regard to the temperatures for the forward and reverse transitions. The reflectivity data shown in Figs, 1 and 2(b) are also in good agreement. The reflectivities indicate that the phase change is almost completely reversible. The peak reflectivity in Fig. 1 has decreased from 0.494 to 0.443 after one temperature cycle. Subsequent cycles produce little further decrease in $R$. In Fig. 2(b), $R$ decreases from 0.492 to 0.453 after one cycle. However, as shown in the figure, $R$ increases gradually after annealing at room temperature. We have not cycled below room temperature.

TABLE I. Bond lengths $(\AA)$ for the polydiacetylene backbone:<smiles>[R]C(C)C([R])[C]C([R])C([R])[CH]C</smiles>

\begin{tabular}{lllll}
\hline \hline & $\begin{array}{l}\text { Ideal } \\
\text { acetylene } \\
\text { structure }\end{array}$ & PTS $^{\mathrm{b}}$ & TCDU $^{\mathrm{c}}$ & $\begin{array}{l}\text { Ideal } \\
\text { butatriene } \\
\text { structure }\end{array}$ \\
\hline $\mathrm{C}_{1}-\mathrm{C}_{2}$ & 1.45 & 1.43 & 1.38 & 1.35 \\
$\mathrm{C}_{2}-\mathrm{C}_{3}$ & 1.20 & 1.21 & 1.24 & 1.26 \\
$\mathrm{C}_{4}-\mathrm{C}_{1}$ & 1.34 & 1.36 & 1.42 & 1.48 \\
$\begin{array}{l}\text { Chain } \\
\text { repeat }\end{array}$ & 4.91 & 4.89 & 4.87 & 4.87 \\
\hline \hline
\end{tabular}

${ }^{\mathrm{a}}$ Estimates from Ref. 5.

${ }^{b_{\text {Data }}}$ from Kobelt and Paulis. ${ }^{3}$

'Data from Enklemann and Lando. ${ }^{4}$

${ }^{d}$ Data from Ref. 6 for tetraphenyl butatriene.

-The indicated change in chain repeat dimension is not significant within the uncertainties of the four sets of bond length data. 


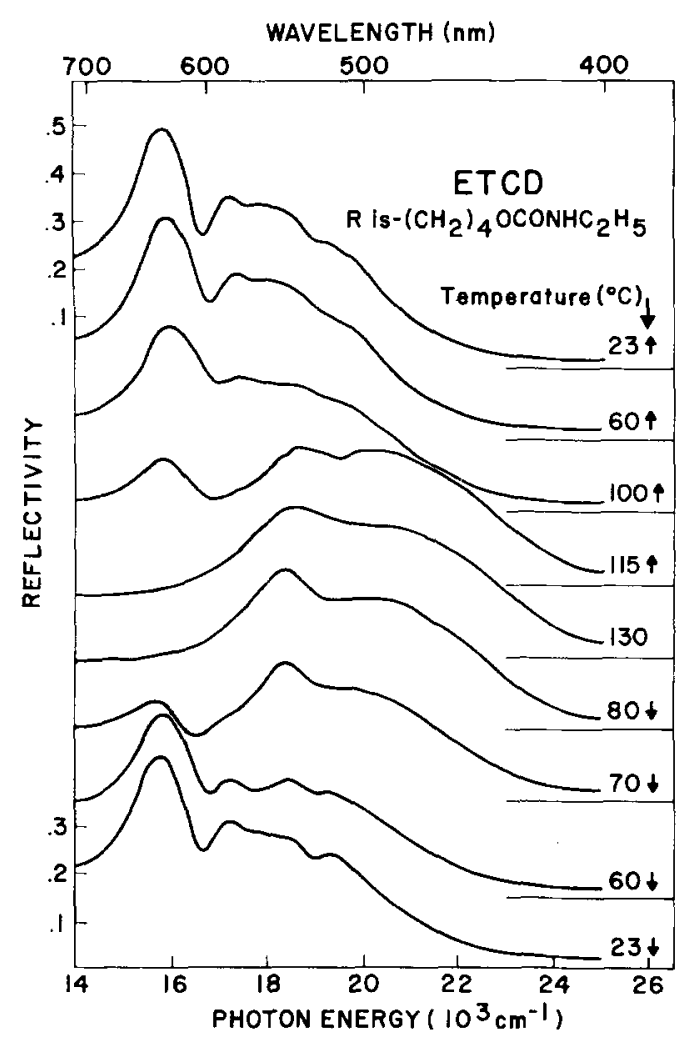

FIG. 1. Normal incidence reflection spectra of ETCD as a function of temperature. The uppermost curve is obtained for the as-polymerized material. The reflectivity scales on the left refer to the room temperature spectra. The origins of each spectrum are indicated by the horizontal lines on the right. The temperature is controlled to within $\pm 0.1^{\circ}$ at the indicated values. The arrows beside the temperatures are included to indicate position on the hysteresis loop (Fig. 2). The incident light is polarized parallel to the chain direction with a bandpass of $50 \mathrm{~cm}^{-1}$ for all reflection data reported here and in the figures to follow. Reflection spectra obtained with perpendicular polarization were featureless throughout this temperature range.

In Fig. 3, we compare the reflection spectra of ETCD, above and below the phase transition, to those of PTS ${ }^{11}$ and TCDU ${ }^{13}$ measured on the same apparatus. The highly structured, room temperature spectrum of ETCD is seen to be quite similar to that of PTS, which is best represented by the acetylene backbone. The high temperature spectrum of ETCD is blue shifted by about $2750 \mathrm{~cm}^{-1}$ and is relatively unstructured, with only two obvious features. This spectrum is quite similar to that of TCDU, which is best represented with a butatriene backbone. This evidence strongly indicates that the electronic structure change in ETCD can be described as an acetylene to butatriene transformation in backbone bonding sequence.

At the present time we can only present a hypothesis for the origin of the acetylene to butatriene transformation. The structural information now available, which is limited to unit cell determinations, suggests that differences in interchain interactions in the two phases of ETCD may explain the electronic structure change. The unit cell parameters are $a=18.30 \pm 0.07, b=4.89 \pm 0.05$, $c=10.78 \pm 0.01 \AA$, and $\beta=95.0^{\circ} \pm 0.2^{\circ}$ for the low temper ature phase, and $a=19.93 \pm 0.09, b=4.83 \pm 0.05, c$ $=9.58 \pm 0.01 \AA$, and $\beta=91.0^{\circ} \pm 0.3^{\circ}$ for the high temper-

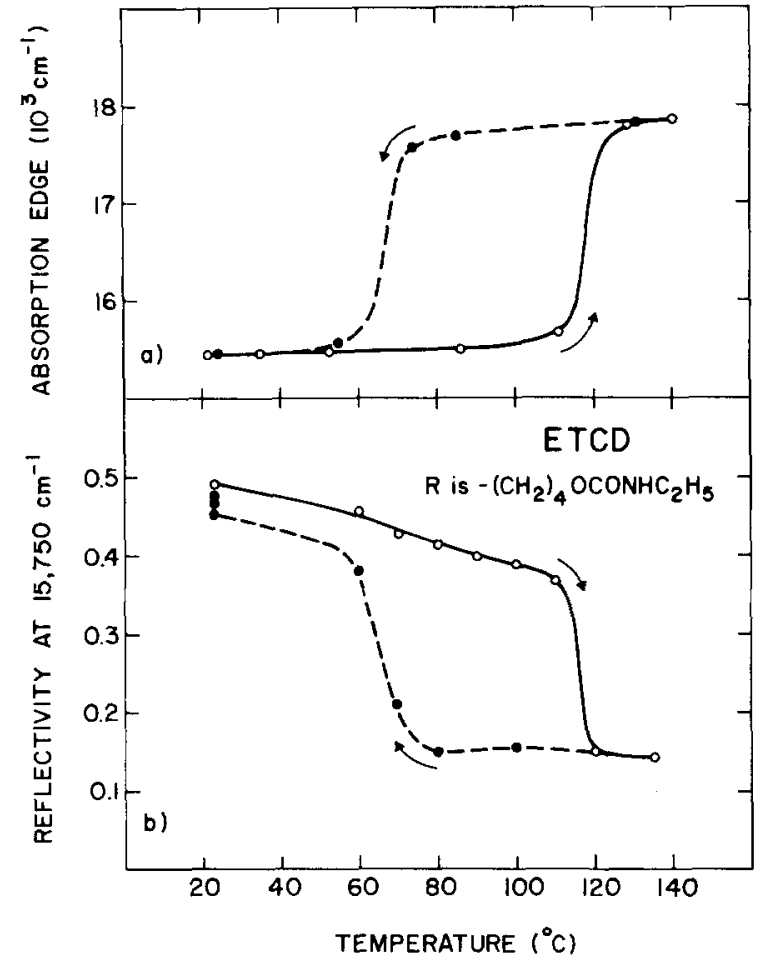

FIG. 2. Hysteresis loops for (a) absorption edge which is arbitrarily defined in a transmission mode and (b) the reflectivity at $15750 \mathrm{~cm}^{-1}$, which is the peak at room temperature. The three closed circles at $23^{\circ} \mathrm{C}$ in (b) refer to measurements taken immediately after the temperature cycle, after annealing at room temperature for $16 \mathrm{~h}$, and after annealing for an additional $40 \mathrm{~h}$ (in order of increasing reflectivity).

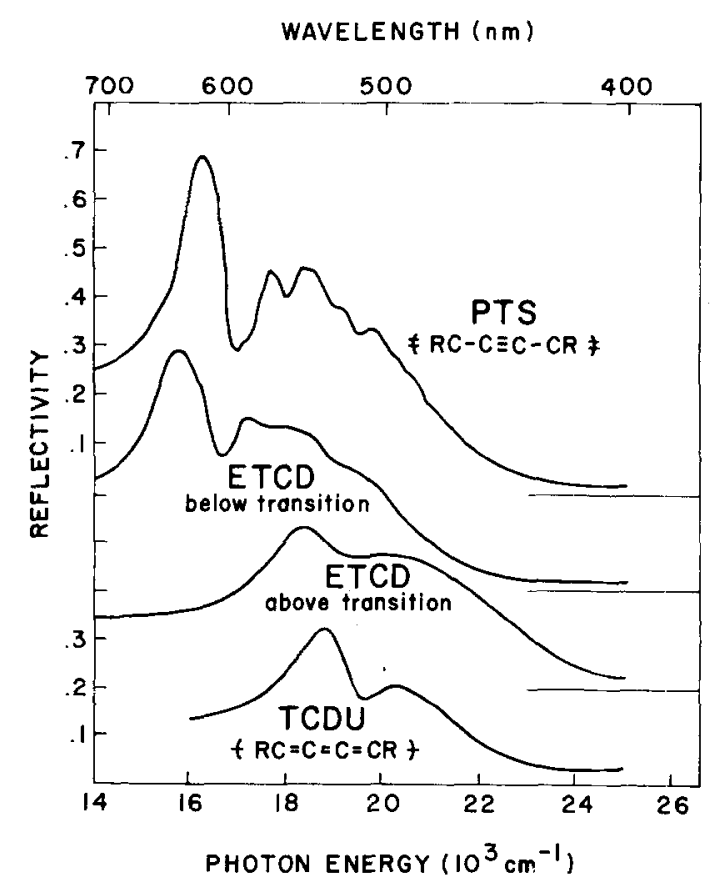

FIG. 3. Normal incidence reflection spectra for PTS, ${ }^{11}$ TCDU, ${ }^{12}$ ETCD below the phase transition, and ETCD above the phase transition. The observed backbone bonding sequences for PTS and TCDU are shown schematically. ${ }^{3,4}$ The ETCD data are the Fig. 1 curves labeled $23 t$ and $80 t$. The displaced origins of the curves are indicated by the horizontal lines on the right. 
ature phase. In both cases the probable space group is $P_{2_{1}} / c$ (from observed systematic absences: $h 0 l$ absent for $l$ odd and $0 k 0$ absent for $k$ odd) with two molecules per unit cell. Two molecules per unit cell in this space group implies that each monomer repeat unit sits on a center of symmetry. The shortest separation between polymer chains occurs in the $c$ direction, between chains which are related by a $2_{1}$ axis. The interchain separations are $5.39 \AA$ for the low temperature phase and 4.79 $\AA$ for the high temperature phase. These separations are much shorter than those observed for other polydiacetylenes which apparently do not undergo a thermally induced acetylene to butatriene transformation. For example, this distance in PTS is $7.5 \AA$. Furthermore, space group and packing considerations show that the $2_{1}$ operation brings the $\pi$-electron density of the $\mathrm{C}_{1}-\mathrm{C}_{2}$ bond (see Table I) in one chain into the same volume as the $\pi$-electron density of the $\mathrm{C}_{2}-\mathrm{C}_{3}$ bond in a neighboring chain. Shortening of the interchain distance, such as occurs at the phase transition, could lead to a redistribution of the $\pi$-electron density and to a new set of equilibrium bond lengths. Qualitatively, the shorter interchain distance in the high temperature phase would tend to favor the butatriene bonding sequence. Though this explanation seems reasonable for ETCD based on the available structural information, in TCDU the shortest interchain separation is fairly large $(6.3 \AA)$ for the room temperature, butatriene phase. ${ }^{4}$ However, there is no structural information available for the low temperature phase of TCDU.

Clearly $x$-ray structure determinations for ETCD above and below the phase transition are required for a complete understanding of the origin of the transformation, as well as for an absolute confirmation of our assignment of an acetylene to butatriene transformation in ETCD. However, the evidence from the reflection spectra, the Raman spectra, ${ }^{7}$ and the available $\mathrm{x}$-ray structures provide a convincing argument for the acetylene to butatriene transformation in both TCDU and ETCD.

It is important to point out that the large blue shift observed in the reflection spectra of ETCD at what we suggest is an acetylene to butatriene transformation is in direct conflict with the current band model description of the polydiacetylenes, which uses a simple Hückel approach. ${ }^{14}$ Based on the bond lengths given in Table I, the Hückel treatment predicts more than a factor of 2 decrease in bandgap in going from an acetylene backbone (PTS bond lengths) to a butatriene backbone (TCDU bond lengths). As has been emphasized elsewhere,${ }^{15-17}$ we feel that any theoretical description of the electronic structure of the polydiacetylenes will almost certainly fail unless excitons are explicitly included.

\section{ACKNOWLEDGMENTS}

We are grateful to A. F. Preziosi for crystal preparation, P. A. Apgar for $\mathrm{x}$-ray measurements, and E. A. Turi for helpful discussions, One of us (H. M.) is indebted to the Deutsche Forschungsgemeinschaft for partial support.

${ }^{1}$ G. Wegner, Z. Naturforsch. Teil B 24, 24 (1969); Makomol. Chem. 145, 85 (1971).

${ }^{2}$ R. H. Baughman, J. Appl. Phys, 43, 4362 (1972); J. Polym. Sci. Polym. Phys. Ed. 12, 1511 (1974)

${ }^{3}$ D. Kobelt and E. F. Paulis, Acta Crystallogr. B 30, 232 (1973).

${ }^{4} \mathrm{~A}$. Enkleman and J. Lando, preprint "Crystal and molecular structure of poly $(5,7$-dodecadiyne-diol-1, 12-bis-phenylurethane)."

${ }^{5}$ M. J. S. Dewar, Hyperconjugation (Ronald, New York, 1962).

${ }^{6} \mathrm{Z}$. Berkovitch-Yellin and L. Leiserowitz, J. Am. Chem. Soc. 97, 5627 (1975).

${ }^{7} \mathrm{Z}$. Iqbal, R. R. Chance, and R. H. Baughman, J. Chem. Phys. 66, 5520 (1977).

${ }^{8}$ G. J. Exarhos, W. M. Risen, and R. H. Baughman, J. Am. Chem. Soc. 98, 481 (1976).

${ }^{9}$ R. R. Chance, R. H. Baughman, A. F. Preziosi, and E. A. Turi, Bull. Am. Phys. Soc. 22, 408 (1977).

${ }^{10} \mathrm{C}$. J. Eckhardt and J. Merski, Surf. Sci. 37, 937 (1973).

${ }^{11}$ C. J. Eckhardt, H. Müller, J. Tylicki, and R. R. Chance, J. Chem. Phys. 65, 4311 (1976).

${ }^{12}$ The monomer crystals were irradiated with $50 \mathrm{Mrad}$ of ${ }^{60} \mathrm{CO}$ gamma rays, yielding crystals which were about $80 \%$ polymer. The residual monomer was solvent extracted for all results presented here.

${ }^{13}$ H. Müller, C. J. Eckhardt, R. R. Chance, and R. H. Baughman, Chem. Phys. Lett, 55, 20 (1977).

${ }^{14}$ E. G. Wilson, J. Phys, C 8, 727 (1975); C. Cojan, G. P. Agrawal, and C. Flytzanis, Phys. Rev. B 15, 909 (1977).

${ }^{15}$ R. R. Chance and R. H. Baughman, J. Chem. Phys. 64, 3889 (1976).

${ }^{16}$ D. E. Parry, Chem. Phys. Lett. 46, 605 (1977); ibid. 38, $341(1976)$

${ }^{17}$ H. Müller and C. J. Eckhardt, J. Chem, Phys. (to be published). 